\title{
VOLUNTARY BINGE-LIKE ETHANOL CONSUMPTION SITE-SPECIFICALLY INCREASES C-FOS IMMUNOEXPRESSION IN MALE C57BL6/J MICE.
}

\author{
Nathan William Burnham
}

A thesis submitted to the faculty at the University of North Carolina at Chapel Hill in partial fulfillment of the requirements for the degree of Master of Arts in Department of Psychology and Neuroscience (Behavioral and Integrative Neuroscience).

Chapel Hill

2017

Approved by:

Todd E. Thiele

Donald T. Lysle

Kathryn J. Reissner 
(C) 2017

Nathan William Burnham

ALL RIGHTS RESERVED 


\begin{abstract}
Nathan William Burnham: Voluntary binge-like ethanol consumption sitespecifically increases c-Fos immunoexpression in male C57BL6/J mice. (Under the direction of Todd E. Thiele)
\end{abstract}

Forced-ethanol exposure, via intraperitoneal injection (i.p.) or gavage, is commonly used in combination with c-Fos quantification to assess binge-like neuronal activity. Voluntary binge-like ethanol consumption-induced neuronal activity is less understood. Using the "drinking-in-the-dark" (DID) paradigm, we assessed the effects of binge-like ethanol consumption on c-Fos immunoreactivity (IR) in brain regions implicated in ethanol intake and compared this to i.p. ethanol-induced c-Fos. To this end, male C57BL/6J mice were divided into four groups: DID-EtOH (20\% v/v), DID-water, i.p.-EtOH (1.5 g/kg), or i.p.-saline $(15 \mathrm{~mL} / \mathrm{kg})$ and experienced one 4-day DID cycle or a single i.p. injection, respectively, prior to sacrifice. Relative to controls, EtOH groups significantly increased cFos IR in several brain regions implicated in neurobiological responses to ethanol. Differences in DID-EtOH and i.p.-EtOH c-Fos were not observed across brain regions examined. These results provide insight into the brain regions that modulate binge-like ethanol intake stemming from DID procedures. 


\section{ACKNOWLEDGEMENTS}

I would like to thank Dr. Montse Navarro, Dr. Jennifer A. Rinker, Dr. Simon A. Marshall, and Dr. Jeffrey J. Olney for their expertise, guidance, and support, as well as Rhiannon Thomas, Corryn Chaimowitz, Timothy Gilliam, and Sonia Sabater for their technical assistance and support. This work was funded by National Institute of Health grants AA013573, AA015148, and AA022048 


\section{TABLE OF CONTENTS}

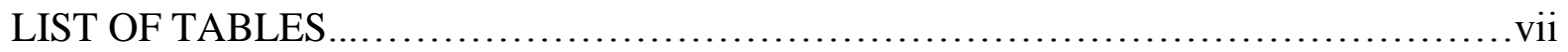

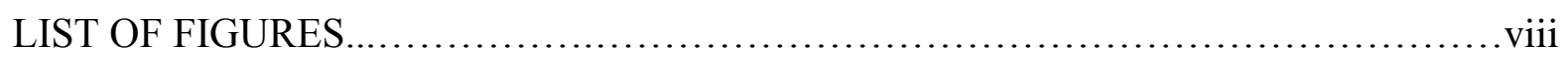

LIST OF ABBREVIATIONS.........................................................

\section{CHAPTER}

I. INTRODUCTION ...................................................

Animal Models of Binge Ethanol Induction..................................

C-Fos as a Measure of Forced-Binge Ethanol-Induced Activity................2

C-Fos Induction Following Voluntary Ethanol Intake........................3

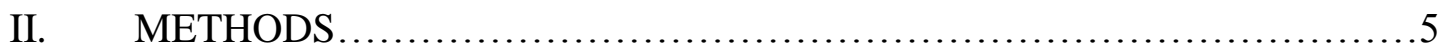

Animals............................................................. 5

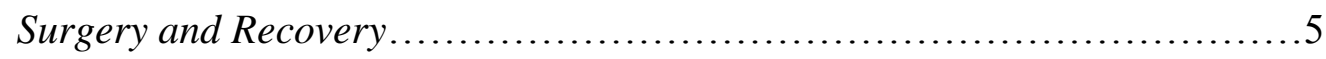

Voluntary consumption: "Drinking-in-the-Dark" Procedure...................6

Forced-binge Episode Induction.......................................6

Immunohistochemistry ................................................

Data Analyses ...................................................... 8

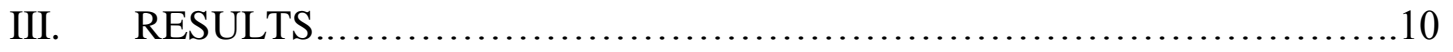

Ethanol Consumption and BECs.......................................10

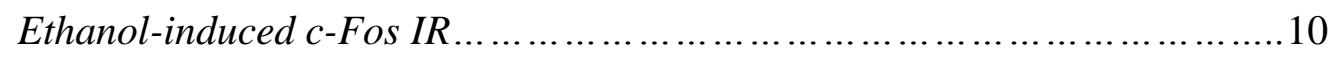

Planned Comparisons of Ethanol-induced c-Fos IR in Brain Regions

Examined ................................................................ 11 


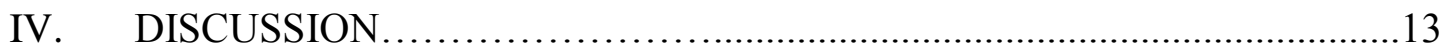

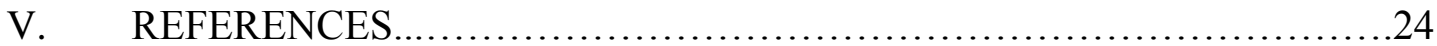




\section{LIST OF TABLES}

Table 1 - Influence of Route of Administration, Solution, or Interaction of Route of Administration and Solution on c-Fos IR Across Brain Regions............................................................ 19 


\section{LIST OF FIGURES}

Figure 1 - C-Fos immunoexpression following voluntary and forced binge episodes.............................................................. 21

Figure 2 - Representative photomicrographs from brain regions where significant c-Fos differences were observed between animals voluntarily binging or consuming water.

Figure 3 - Representative photomicrographs from brain regions where significant c-Fos differences were observed in animals receiving a forced binge (i.p. ethanol) or saline injection 


\section{LIST OF ABBREVIATIONS}

\begin{tabular}{|c|c|}
\hline A 2 & A2 region of the NTS \\
\hline $\mathrm{AcbC}$ & Nucleus accumbens core \\
\hline ANOVA & Analysis of Variance \\
\hline AP & Anterior/posterior \\
\hline $\mathrm{BEC}$ & Blood ethanol concentration \\
\hline BLA & Basolateral Amygdala \\
\hline BNST & Bed Nucleus of the Stria Terminalis \\
\hline $\mathrm{CeA}$ & Central Amygdala \\
\hline CeMPV & Medial Posterioventral portion of the Central Amygdala \\
\hline CRF & Corticotropin-Releasing Factor \\
\hline DID & Drinking-in-the-Dark paradigm \\
\hline DV & Dorsal/Ventral \\
\hline dBNST & Dorsal Bed Nucleus of the Stria Terminalis \\
\hline $\mathrm{EtOH}$ & Ethanol \\
\hline EW & Edinger-Westphal Nucleus \\
\hline Fig & Figure \\
\hline $\mathrm{g} / \mathrm{kg}$ & Gram per kilogram \\
\hline i.p. & Intraperitoneal \\
\hline IR & Immunoreactivity \\
\hline ITF & Inducible Transcription Factor \\
\hline LC & Locus Coeruleus \\
\hline LH & Lateral Hypothalamus \\
\hline
\end{tabular}




\begin{tabular}{|c|c|}
\hline LPBn & Lateral Parabrachial Nucleus \\
\hline$\mu l$ & microliter \\
\hline $\mathrm{mg} / \mathrm{dl}$ & Milligram per deciliter \\
\hline ML & Medial/lateral \\
\hline mPVN & Magnocellular Paraventricular Nuclei \\
\hline mRNA & Messenger Ribonucleic Acid \\
\hline NPY & Neuropeptide-Y \\
\hline NTS & Nucleus of the Solitary Tract \\
\hline PFA & Paraformaldehyde \\
\hline PVA & Paraventricular Nucleus of the Thalamus, anterior \\
\hline PVN & Paraventricular Nucleus of the Hypothalamus \\
\hline PVT & Paraventricular Nucleus of the Thalamus \\
\hline $\mathrm{TH}$ & Tyrosine Hydroxylase \\
\hline TRPV1 & Transient Receptor Potential Channel Vanilloid receptor 1 \\
\hline vBNST & Ventral Bed Nucleus of the Stria Terminalis \\
\hline VTA & Ventral Tegmental Area \\
\hline $\mathrm{v} / \mathrm{v}$ & Volume/volume \\
\hline
\end{tabular}




\section{CHAPTER 1: INTRODUCTION}

The National Institute on Alcohol Abuse and Alcoholism (NIAAA) defines a binge episode as a 2 hour period in which an individual consumes enough alcohol to elicit blood ethanol concentrations (BECs) exceeding 0.08\% (80 mg/dL) (NIAAA, 2004). Previous estimates suggest binge ethanol drinking is the primary route of alcohol consumption for US individuals under the age of 21 , though the majority (70\%) of US binge episodes are attributable to individuals over the age of 26 (Naimi et al., 2003). Unsurprisingly, researchers have linked regular binge drinking to numerous short-term consequences, such as accidental injury (Gmel et al., 2006) and long-term consequences including heart disease, high blood pressure, and type-2 diabetes (Fan et al., 2008). Furthermore, individuals who binge drink early in life are at greater risk of developing alcohol dependence later in life (Miller et al., 2007, Hingson et al., 2005, Rubinsky et al., 2010). Accordingly, identification of neurochemical pathways that modulate binge drinking is of utmost priority as such knowledge could prove beneficial in determining pharmaceutical treatments for bingebehavior prevention.

\section{Animal Models of Binge Ethanol Induction}

Many existing models of binge drinking in rodents involve forced exposure techniques, such as intragastric gavage and intraperitoneal administration, though these methods inherently fail to model voluntary consumption observed in humans. Recently, researchers have adopted a preclinical model of voluntary binge-like ethanol consumption 
termed "drinking-in-the-dark" (DID), a 4-day paradigm involving C57BL/6J mice that has been demonstrated to promote high levels of consumption and reliably generate BECs exceeding 80 mg/dL (Rhodes et al., 2005, Rhodes et al., 2007, Thiele and Navarro, 2014). Using this paradigm, researchers have shown that ethanol recruits a variety of neurochemical systems (Sprow and Thiele, 2012). Furthermore, several brain regions have been implicated in modulating binge-like ethanol intake. For example, in response to binge-like ethanol drinking CRF and NPY levels are increased or decreased, respectively, in the bed nucleus of the stria terminalis (BNST) (Pleil et al., 2015), CRF levels are increased within the central amygdala (CeA) and ventral tegmental area (VTA) (Lowery-Gionta et al., 2012, AlbrechetSouza et al., 2015), NPY levels are reduced in the CeA (Sparrow et al., 2012), and orexin levels are reduced in the lateral hypothalamus (LH) (Olney et al., 2015).

\section{C-Fos as a Measure of Forced-Binge Ethanol-Induced Activity}

Numerous studies have measured neuronal activation following ethanol administration via quantification of inducible transcription factors (ITFs), such as c-Fos. Assessment of ethanol-induced c-Fos expression has been studied using a variety of ethanolexposure paradigms, though ethanol exposure at binge-like levels has most frequently been modeled via intragastric and intraperitoneal administration techniques. For example, researchers have shown that intragastrically-administered binge-like episodes increase c-Fos immunoreactivity (IR) in various brain regions including the CeA (Leriche et al., 2008, Lee et al., 2011), the locus coeruleus (LC), the A1-A2 cell groups, and adrenergic C1-C3 cell groups (Lee et al., 2011). Likewise, ethanol administered intraperitoneally (i.p.) increases cFos IR in the nucleus of the solitary tract (NTS) (Thiele et al., 2000), Edinger-Westphal 
nucleus (EW) (Turek and Ryabinin, 2005), and the paraventricular nucleus of the hypothalamus (PVN), CeA, dBNST, and EW (Knapp et al., 2001).

\section{C-Fos Induction Following Voluntary Ethanol Intake}

Assessment of c-Fos induction following voluntary ethanol consumption in limitedaccess consumption or operant paradigms (Bachtell et al., 1999, Weitemier et al., 2001, Sharpe et al., 2005) or chronic consumption in two-bottle choice paradigms (Li et al., 2010, Sajja and Rahman, 2013) indicate that voluntary consumption can region-specifically increase c-Fos expression. One notable previous study examined c-Fos IR following limitedaccess consumption in mice that generated BECs that exceeded binge-like levels (i.e., greater than $80 \mathrm{mg} / \mathrm{dL}$ ). Mice drank $2.9 \mathrm{~g} / \mathrm{kg}$ of ethanol from a $10 \%$ ethanol/10\% sucrose solution and achieved BECs of $\sim 250 \mathrm{mg} / \mathrm{dL}$ over a 30 minute test that began 2.5 hours into the dark cycle (Ryabinin et al., 2003). However, c-Fos IR resulting from binge-like ethanol drinking stemming specifically from DID procedures has not been examined. This is a critical gap in the literature given the popular use of DID procedures in pre-clinical studies (Sprow and Thiele, 2012).

Accordingly, the goal of the present study was to assess the effects of binge-like ethanol intake, using DID procedures, on neuronal activation in various brain regions implicated in alcohol use and abuse, including noradrenergic brainstem structures, extended amygdaloid structures [BNST, CeA, \& basolateral amygdala (BLA)], the LH, and the EW. To this end, cFos synthesized in response to voluntary binge-like ethanol consumption was compared to voluntary water consumption, as well as forced binge-like ethanol exposure via i.p. injection of ethanol. Finally, we assessed tyrosine hydroxylase (TH)/c-Fos co-expression in the LC and A2 nucleus of the NTS to determine the percentage of noradrenergic cells activated 
within each region and to compare with one of our previous studies (Thiele et al., 2000) that examined similar labeling in rats receiving an ethanol injection. 


\section{CHAPTER 2: METHODS}

\section{Animals}

Male C57BL/6J mice ( $\mathrm{n}=50$, stock \# 000664, Jackson Laboratory), 6 - 8 weeks old were housed in individual home cages with a room temperature maintained at $22^{\circ} \mathrm{C}$ and a 12:12 hr reverse light/dark cycle with lights off at $0830 \mathrm{hr}$. Prolab® RMH 3000 (Purina labDiet@; St. Louis, MO) and water were available ad libitum except where noted. All protocols were conducted under National Institute of Health guidelines and were approved by the University of North Carolina Institutional Animal Care and Use Committee.

\section{Surgery and Recovery}

Prior to surgery, mice were weighed and anesthetized using a ketamine $(66.7 \mathrm{mg} / \mathrm{kg}$; Henry Schein, Dublin, $\mathrm{OH})$ and xylazine $(6.67 \mathrm{mg} / \mathrm{kg})$ cocktail administered by i.p. injection. Mice received $0.1 \mathrm{~mL} 1 \%$ Lidocaine $\mathrm{HCl}$ (Hospira, Inc., Lake Forest, IL) subcutaneously above the skull. Mice received unilateral injections of green and red Retrobeads $(0.2-0.3$ $\mu \mathrm{L} /$ site; Lumafluor, Durham, NC) aimed at ipsilateral BNST (AP +0.15, ML -1.00, DV -4.8; no angle) and VTA (AP -3.1, ML -0.50, DV -4.6; no angle) structures via Hamilton syringe. Following surgery conclusion, animals received topical analgesic cream containing Lidocaine and Prilocaine (25mg/g of each; Akorn Pharmaceuticals, Gurnee, IL). Subjects recovered for two weeks before undergoing testing. However, the size and spread of RetroBead injection sites proved highly variable across animals, complicating quantification 
and interpretation of pathway involvement. Accordingly, RetroBead labeling analyses were excluded.

\section{Voluntary consumption: "Drinking-in-the-Dark" Procedure}

A four-day drinking-in-the-dark (DID) paradigm was used. Briefly, animal weights were collected 30 minutes prior to homecage water bottle removal. Beginning three hours into the dark cycle, homecage water bottles were removed and replaced with $10 \mathrm{~mL}$ plastic pipettes (calibrated to $0.1 \mathrm{~mL}$ ) containing either unsweetened ethanol $(20 \%$, v/v) or tap water ( $n=15$ /group). Following the two hour free-access period, pipettes were removed and homecage water bottles were returned. Pipette volume was measured to the nearest $0.1 \mathrm{~mL}$ at homecage water bottle removal and replacement. Ethanol consumption was assessed as the difference in volume measured at the beginning of the session versus the end. On the fourth day tail blood samples were collected from each animal immediately after ethanol access and analyzed via an alcohol analyzer (Analox Instruments, Lunenburg, MA) to assess BECs. Animals were then perfused with $4 \%$ paraformaldehyde.

\section{Forced-binge Episode Induction}

The remaining mice $(n=20 / 50)$ were randomly divided into two groups of 10 , with one group receiving a single i.p. injection of $0.9 \%$ saline $(15 \mathrm{~mL} / \mathrm{kg})$ and the other receiving a $1.5 \mathrm{~g} / \mathrm{kg}$ dose of ethanol $(13 \% \mathrm{v} / \mathrm{v} ; 15 \mathrm{~mL} / \mathrm{kg})$. For this experiment, animals were not habituated to injection procedures to avoid potential sensitization of stress responses associated with repeated handling and injection. Like the mice used in DID procedures, these mice were single-housed from arrival until sacrifice. On injection day, mice were removed from home cages, injected with either saline or ethanol at the time corresponding to DID onset for animals in the voluntary consumption group, and then placed back into home cages 
for two hours. Mice receiving i.p. injections were perfused two hours post-injection, mimicking the duration of ethanol exposure mice received in the DID cohort.

\section{Immunohistochemistry}

Mice were transcardially perfused with phosphate buffered saline (PBS) for 3 minutes followed immediately by $4 \%$ paraformaldehyde (PFA) for 7 minutes using a Masterflex L/S perfusion pump (catalogue \#7200-12, Cole-Parmer, Vernon Hills, IL). Brains were collected and postfixed in approximately $15 \mathrm{~mL} 4 \%$ PFA for $24 \mathrm{~h}$. Next, brains were cryoprotected in approximately $15 \mathrm{~mL}$ PBS solution containing $20 \%$ sucrose and $0.01 \%$ sodium azide (catalogue \#S2002, Sigma-Aldrich, St. Louis, MO). Brains were sectioned into $40 \mu \mathrm{m}$ slices via vibratome (model VT1000 S, Leica Biosystems, Buffalo Grove, IL). Tissue was placed in cryopreserve and stored in a $-20^{\circ}$ freezer for later retrieval.

Sections underwent three $30 \mathrm{~s}$ rinses prior to overnight incubation in rabbit anti-cFos (catalogue \#sc-52, lot\# D0512, Santa Cruz Biotechnology, Dallas, TX), diluted 1:20,000 in PBS with $0.25 \%$ Triton-X (Fisher Scientific, Waltham, MA) and $0.01 \%$ sodium azide. Following two $30 \mathrm{~s}$ rinses, sections incubated for $30 \mathrm{~min}$ in biotinylated donkey anti-rabbit secondary (1:1k; code \#711-065-152, Jackson Immunoresearch, West Grove, PA) diluted 1:1000 in PBS. Sections underwent four additional rinses before incubating for $1 \mathrm{~h}$ in Vectastain ABC kit (Vector Laboratories, Burlingame, CA) diluted 1:1000 in PBS. Sections rinsed twice before exposure to PBS containing $0.05 \%$ diaminobenzidine tetrahydrochloride hydrate (DAB; catalogue \#D5637, Sigma-Aldrich, St. Louis, MO), 0.05\% ammonium nickel (II) sulfate hexahydrate (catalogue \#A-1827, Sigma-Aldrich), and 0.01\% hydrogen peroxide. The stain was terminated via rinses in PBS containing $0.01 \%$ sodium azide. Next, were placed into a 1:20,000 dilution of sheep anti-tyrosine hydroxylase $(\mathrm{TH}$; catalogue \#AB1542, 
EMD Millipore, Billerica, MA). TH staining procedures were identical to c-Fos staining with the exceptions that the secondary step utilized donkey anti-sheep (1:1k; code \#713-065-147, Jackson Immunoresearch) and nickel was omitted during the DAB step.

\section{Data Analyses}

Among the 15 mice receiving ethanol in the DID procedure, $8(53 \%)$ exceeded the criteria for a binge episode $(80 \mathrm{mg} / \mathrm{dl})$ with a mean consumption ethanol consumption of 3.98 $\pm 0.47 \mathrm{~g} / \mathrm{kg}$ and $\mathrm{BEC}$ of $121.63 \pm 27.57 \mathrm{mg} / \mathrm{dl}$. The 7 mice who failed to binge (consumption: $3.00 \pm 0.77 \mathrm{~g} / \mathrm{kg}$; BEC: $40.23 \pm 24.04 \mathrm{mg} / \mathrm{d}$ ) were excluded from further analyses as our objective was to assess c-Fos expression in response to binge-like levels of ethanol consumption. Failed immunostaining missing or partial sections further limited the number of animals in subsets of analyses. Counts represent the average of bilateral IR within $2-3$ tissue slices per brain region for each animal. Brain region identification was based upon coordinates indicated in The Mouse Brain in Stereotaxic Coordinates atlas (Franklin and Paxinos, 1997). Slice were matched to images in the atlas corresponding to AP position relative to bregma (dBNST \& vBNST: $+0.38,+0.26,+0.14$; CeA \& BLA: $-1.06,-1.34,-1.58$; PVA (paraventricular nucleus of the thalamus, anterior): $-0.22,-0.46,-0.58 ;$ PVT (paraventricular nucleus of the thalamus): $-1.22,-1.46,-1.82 ; \mathrm{EW}:-3.4,-3.64,-3.8 ; \mathrm{LH}$ (lateral hypothalamus): -1.22, -1.34, -1.46; LC: -5.34, -5.4, -5.52; 1PBn: -5.2, -5.34; A2: $7.32,-7.48,-7.56)$

Brain regions from one animal (mouse 1) in the DID-water cohort were photomicrographed and encircled in Adobe Illustrator (San Jose, CA) based upon boundaries established in the brain atlas at each level of AP listed above. To maintain consistent boundary identification of brain regions across animals, experimenter-encircled boundaries 
from mouse 1 were overlayed with all other mice. Differences in IR within a given brain region were assessed via 2 (route of administration) x 2 (solution) multivariate ANOVA, and t-tests were used for planned comparisons. All counts were performed by an individual blind to experimental conditions and are labeled as mean \pm standard error. Analyses were performed in SPSS (SPSS Inc., Chicago, IL) and GraphPad Prism 6.0 (GraphPad Software, La Jolla, CA). 


\section{CHAPTER 3: RESULTS}

\section{Ethanol consumption and BECs}

With DID procedures mice $(\mathrm{n}=8)$ drank $3.98 \pm 0.47 \mathrm{~g} / \mathrm{kg}$ of ethanol and had BECs of $121.63 \pm 27.57 \mathrm{mg} / \mathrm{dl}$. While tail blood samples were not collected prior to perfusion for i.p.-injected mice used to assess c-Fos IR, a follow-up study with male C57BL/6J mice ( $\mathrm{n}=$ 9) confirmed that an i.p. injection of a $1.5 \mathrm{~g} / \mathrm{kg}$ dose of ethanol (13\% v/v) produced BECs 2-h post injection $(100.23 \pm 44.54 \mathrm{mg} / \mathrm{dl})$ that were similar to BECs achieved by binge drinking mice. A t-test comparing BECs between DID and i.p. injected mice failed to achieve significance $[\mathrm{t}(15)=1.172, \mathrm{p}=0.26]$.

\section{Ethanol-induced c-Fos IR}

Fig. 1A shows the average number of c-Fos positive nuclei per brain region following binge-like ethanol drinking (DID) versus water consumption, and Fig. 1B shows the average number of c-Fos-positive nuclei per brain region following a single i.p. injection of a $1.5 \mathrm{~g} / \mathrm{kg}$ dose of ethanol dose versus the group given i.p. injection of saline. Photomicrographs from brain regions exhibiting significant increases of ethanol-induced c-Fos IR for the DID and i.p. injection procedures are presented in Figs. 2 and 3, respectively. Table 1 shows the statistical results from a 2 (route of administration) x 2 (solution) multivariate ANOVA that assessed differences in IR within in the brain regions examined. There we several significant main effects of route of administration, reflecting great overall c-Fos IR associated with the i.p. injection procedure in the BLA (DID $=36.83 \pm 5.73$; i.p. $=62.89 \pm 4.18), \mathrm{EW}(\mathrm{DID}=$ 
$17.83 \pm 2.18$; i.p. $=25.63 \pm 1.59), 1 \mathrm{PBn}(\mathrm{DID}=24.58 \pm 10.56$; i.p. $=69.93 \pm 7.71)$, and $\mathrm{A} 2$ $(\mathrm{DID}=5.75 \pm 3.39$; i.p. $=25.36 \pm 2.47)$, and overall great c-Fos IR associated with DID procedure in the $\mathrm{LH}(\mathrm{DID}=76.75 \pm 5.43$; i.p. $=50.43 \pm 3.96)$ and $\mathrm{LC}(\mathrm{DID}=8.42 \pm 1.13$; i.p. $=5.02 \pm 0.82$ ). There were also several significant main effects of solution, reflecting great overall c-Fos IR associated with ethanol exposure relative to vehicle in the dBNST $($ ethanol $=69.55 \pm 5.40 ;$ vehicle $=36.38 \pm 4.95), \operatorname{vBNST}($ ethanol $=47.69 \pm 3.00 ;$ vehicle $=$ $28.03 \pm 2.75), \mathrm{CeA}($ ethanol $=41.39 \pm 5.54 ;$ vehicle $=23.19 \pm 5.08)$, BLA $($ ethanol $=62.53 \pm$ 5.23; vehicle $=37.20 \pm 4.79), \mathrm{LH}($ ethanol $=73.08 \pm 4.96$; vehicle $=54.10 \pm 4.55), \mathrm{EW}$ $($ ethanol $=34.25 \pm 1.99 ;$ vehicle $=9.22 \pm 1.83), \mathrm{LC}($ ethanol $=9.92 \pm 1.03 ;$ vehicle $=3.52 \pm$ $0.95)$, and A2 (ethanol $=24.31 \pm 3.09$; vehicle $=6.8 \pm 2.83)$. Interestingly, there were no significant interaction effects between the route of administration and solution main effects, suggesting that increased c-Fos IR stemming from ethanol exposure did not significantly depend on the route of administration.

\section{Planned comparisons of ethanol-induced c-Fos IR in brain regions examined}

Because we were interested in making direct comparisons of c-Fos IR between ethanol and vehicle groups we performed plan comparisons at each brain region examined with DID procedures (Fig. 1A) and i.p. injection procedures (Fig. 1B). T-tests showed that, relative to water controls, voluntary binge-like ethanol drinking significantly increased c-Fos labeling in dBNST [t(11) $=4.11, p=0.002], \operatorname{vBNST}[\mathrm{t}(11)=2.22, p=0.048], \mathrm{CeA}[\mathrm{t}(9)=$ $5.45, p=0.0004]$, PVT [t(12) $=2.76, p=0.017], \mathrm{LH}[\mathrm{t}(6)=1.59, p=0.032], \mathrm{EW}[\mathrm{t}(14)=$ $8.25, p<0.0001], \mathrm{LC}[\mathrm{t}(15)=3.30, p=0.005]$, and the $\mathrm{A} 2[\mathrm{t}(12)=31.48, p<0.0001]$. No significant differences were detected in the BLA [t(9) $=0.90, p=0.39]$, PVA $[\mathrm{t}(12)=0.50, p$ $=0.62]$, or $\operatorname{PBn}[\mathrm{t}(6)=1.71, p=0.138]$. Double immunohistochemistry indicated that 
approximately $35-40 \%$ of A2 TH-positive neurons co-expressed c-Fos in DID binge animals, whereas approximately $3-5 \%$ of $\mathrm{TH}$-positive A2 neurons co-expressed c-Fos in water drinking controls. Additionally, approximately 40-50\% of LC TH-positive cells co-expressed c-Fos in DID binge animals, whereas approximately 5-10\% of TH-positive LC neurons coexpressed c-Fos in water drinking controls.

T-tests indicated that an ethanol injection produced significant increases of c-Fos IR, relative to saline-injected controls, in the $\operatorname{dBNST}[\mathrm{t}(13)=4.88, p<0.001]$, $\operatorname{vBNST}[\mathrm{t}(13)=$ $4.20, p=0.001]$, CeA [t(12) $=3.74, p=0.003]$, BLA [t(12) $=2.98, p=0.011]$, PVT [t(13) $=$ $3.33, p=0.005], \mathrm{LH}[(11)=3.31, p=0.007], \mathrm{EW}[\mathrm{t}(15)=10.90, p<0.001], \mathrm{LC}[\mathrm{t}(15)=$ $4.15, p<0.001]$, and the $\mathrm{A} 2[\mathrm{t}(15)=5.81, p<0.001]$. No significant changes in $\mathrm{c}$-Fos IR were detected in the PVA $[\mathrm{t}(13)=1.77, p=0.100]$ or the $\operatorname{PBn}[\mathrm{t}(11)=1.58, p=0.142]$. Approximately 60-70\% of TH-positive A2 neurons co-expressed c-Fos in ethanol-injected animals. Conversely, nearly $15 \%$ of TH-positive A2 neurons co-expressed c-Fos in salineinjected animals. Similarly, about 60-70\% of TH-positive LC neurons co-expressed c-Fos in ethanol-injected mice, whereas about 10-20\% of TH-positive LC neurons co-expressed c-Fos in saline-injected mice. 


\section{CHAPTER 4: DISCUSSION}

Importantly, voluntary binge-like ethanol consumption and i.p. injection of a $1.5 \mathrm{~g} / \mathrm{kg}$ dose of ethanol were associated with similar BECs allowed us to make meaningful comparisons of c-Fos expression across brain regions and conditions. When brains were collected immediately after ethanol drinking on day 4 of the DID test, elevated c-Fos IR was observed in mice that voluntarily binged relative to the water drinking control group. Specifically, mice that voluntarily binged displayed elevated c-Fos IR in areas of the extended amygdala (dBNST, vBNST, CeA), a major relay center from midbrain to cortex in the PVT (Kelley et al., 2005), EW, LC, and the A2 region of the NTS (Fig. 1A). Interestingly, these same brain regions showed ethanol-induced c-Fos IR in mice given forced i.p. ethanol injections, though there was additionally a significant elevation of c-Fos IR in the BLA of ethanol-injected mice (Fig. 1B), which was not evident in mice engaging in binge-like ethanol consumption. Importantly, the absence of significant interaction effects between the route of administration and solution main effects suggests that increased c-Fos IR stemming from ethanol exposure did not significantly depend on the route of administration.

There are caveats that need to be addressed. First, though BECs at sacrifice did not differ between the different route of administration procedures, the onset of peak BEC likely differed between procedures. Further, the DID procedure was associated with 4-days of ethanol exposure while i.p. injection of ethanol occurred once. Though we cannot completely 
rule out the potential influence of these procedural differences on our c-Fos IR data, these concerns are somewhat tempered by the observation that ethanol-induced c-Fos IR did not differ significantly between routes of administration. An additional concern is that mice underwent cranial surgery for placement of Retrobeads into the BNST and VTA. While we cannot rule out the possibility that prior surgery may have influence subsequent effects of ethanol on c-Fos IR, many studies that use DID procedures involve prior surgery before consumption studies, and thus our study is particularly informative for studies the incorporate surgery.

In 4 of the brain regions examined (the BLA, EW, IPBn, and A2) overall c-Fos IR was greater following i.p. relative to DID procedures. The transient receptor potential channel vanilloid receptor 1 (TRPV1) is a cation channel responsible for detection and transduction of noxious chemical and thermal stimuli (Ellingson et al., 2009, Caterina et al., 1997, Szallasi and Blumberg, 2007). TRPV1 is found in the peritoneum, where i.p. injections of capsaicin stimulate TRPV1 and subsequent abdominal nociception (Trevisan et al., 2013). It is possible that activation of the TRPV1 system by injection of ethanol and saline contributed to the increased c-Fos IR in the BLA, EW, IPBn and A2. Consistent with this idea, intraperitoneally-administered hypertonic saline has been found to increase c-Fos protein (Ceccatelli et al., 1989) and mRNA (Sharp et al., 1991) in several brain regions. Additionally, potential induction of stress stemming from pain and/or the involuntary nature of i.p. injection could have also played a role. However, that fact that we observed overall greater levels of c-Fos IR in the LH and LC with DID, relative to i.p., procedures, and nodifferences in c-Fos IR on other regions examined, suggest that potential contributions of pain and/or stress to i.p. injection-induced c-Fos IR are brain-region specific. 
Previous studies have shown that voluntary ethanol consumption in limited access sessions, wherein water-restricted C57BL6/J mice were allotted 30 min to consume either $10 \%$ ethanol (2.5 hr into dark cycle; Sharpe et al., 2005) or $10 \%$ ethanol/10\% sucrose (Bachtell et al., 1999) solutions, increased c-Fos IR in the nucleus accumbens core (AcbC), the medial posterioventral portion of the central nucleus of the amygdala (CeMPV; Bachtell et al., 1999), and the EW (Bachtell et al., 1999, Sharpe et al., 2005, Weitemier et al., 2001). Similarly, we found that a single binge-like drinking cycle with DID procedures increased cFos IR in the CeA and EW, though our results indicate a DID-elicited binge-like episode can increase c-Fos IR in regions, such as the BNST and PVT, which were not detected with 30 min limited access procedures (Sharpe et al., 2005). In combination with chronic voluntary ethanol consumption using 24-h, two-bottle choice procedures, where ethanol consumption increased FosB presence in the AcbC, dorsolateral striatum, orbitofrontal cortex (Li et al., 2010), and ventral striatum (Sajja and Rahman, 2013), our results expand our understanding of how voluntary ethanol consumption, and more specifically, voluntary binge-like ethanol consumption, recruits that activity of various brain regions.

Interestingly, in a study with C57BL/6J mice that used a 10\% ethanol/10\% sucrose solution which promoted binge-like drinking ( $2.9 \mathrm{~g} / \mathrm{kg}$ of ethanol) and associated BECs $(\sim 250 \mathrm{mg} / \mathrm{dL})$ over a 30 minute test, there was no evidence of increased c-Fos IR in areas of the amygdala and reduced c-Fos IR in the LH relative to water dining mice, both observations that are inconsistent with our findings. Similar to our results though, they did find increased c-Fos IR in the EW (Ryabinin et al., 2003). Numerous procedure differences between the studies described above reinforcing the idea that ethanol-induced c-Fos IR is 
procedure specific and highlight the novelty of the present work which reveals neuronal activity specific to DID procedures.

In assessing TH and c-Fos co-expression in noradrenergic stimuli (A2 and LC), we found that voluntary water consumption produced near-zero co-expression in both structures. Conversely, the percentage of co-expression was elevated among animals that binge drank ethanol (A2: 35-40\%; LC: 40-50\%). I.p. ethanol injections yielded a slightly greater coexpression pattern (A2: 60-70\%; LC: 60-70\%) than saline-injected animals. These expression patterns are in line with previously reported findings in male rats, where i.p. ethanol injections elicited $\sim 35-60 \%$ and $\sim 65-75 \%$ co-expression in the LC and A2, respectively (Thiele et al., 2000). The LC innervates numerous brain regions including the orbitofrontal cortex, medial prefrontal cortex, anterior cingulate, lateral hypothalamus, amygdala, and ventral tegmental area, among others (Chandler et al., 2014, Foote et al., 1983), while the A2 innervates the BNST, accumbens shell, lateral hypothalamus, and ventral tegmental area, among others (Delfs et al., 2000, Mejias-Aponte et al., 2009, Smith and Aston-Jones, 2008). Given the high levels of TH/c-Fos co-expression in A2 and LC, as well as increased c-Fos in regions innervated by the A2 and/or LC (lateral hypothalamus, BNST, amygdala), noradrenergic circuitry may play an important role in voluntary ethanol consumption. Accordingly, our lab is currently investigating possible involvement of noradrenergic circuitry in voluntary binge-like ethanol consumption.

An examination of our c-Fos IR data indicates that in many brain regions c-Fos IR was relatively high under baseline water drinking and saline injection conditions. An inherent aspect to the DID procedure is that behavioral assessment is performed during the dark cycle, when mice are more active and consume the majority of their daily food and water. In rats, 
others have demonstrated that c-Fos mRNA expression oscillates depending on time of day, with increased c-Fos activity occurring at night and weak activity during rest hours (GrassiZucconi et al., 1993). Moreover, light/dark exposure can site-specifically influence c-Fos IR in the rat brain, with the "lights-on" phase increasing c-Fos presence in the suprachiasmatic nuclei (Aronin et al., 1990) and the "lights-off" phase increasing c-Fos IR in various regions including the PVT, magnocellular paraventricular nuclei $(\mathrm{mPVN})$, and dorsomedial nuclei (Choi et al., 1998). Interestingly, in reviewing the forced binge-induced c-Fos literature, this work was almost exclusively conducted in the lights-on portion of rodent light cycles. Thus, higher-than-anticipated basal c-Fos IR in the control conditions of our studies may potentially be a product of collecting measures during the dark cycle.

Finally, we must note that our procedures were performed in males exclusively. Researchers have shown that adult female C57BL/6J mice voluntarily consume significantly more ethanol $(\mathrm{g} / \mathrm{kg})$ than male counterparts in intermittent 24-h access paradigms (Hwa et al., 2011), under conditions of food or water deprivation (Middaugh and Kelley, 1999), and in two-bottle choice paradigms with 2-h limited access sessions (Vetter-O'Hagen et al., 2009) or continuous access (Yoneyama et al., 2008). Thus, future studies should investigate potential sex differences in voluntary binge-induced neuronal activation.

Taken together, our results indicate that a single 4-day binge-like ethanol drinking session with DID procedures region-specifically activated c-Fos IR in brain areas implicated in neurobiological responses to ethanol and ethanol drinking. Binge-like ethanol drinking mice and mice given i.p. injection of ethanol displayed similar BECs, increasing our ability to make comparisons of c-Fos IR between the different ethanol exposure paradigms. DID and i.p. injection procedures increased c-Fos IR in similar regions, and the absence of significant 
interaction effects between the route of administration and solution main effects suggest that increased c-Fos IR stemming from ethanol exposure did not significantly depend on the route of administration. This work provides insight for future studies aimed at identifying the brain regions and circuitry involved in modulation of binge-like ethanol drinking, particularly those employing DID procedures. 
Table 1: Influence of Route of Administration, Solution, or Interaction of Route of Administration and Solution on c-Fos IR Across Brain Regions.

\begin{tabular}{|c|c|c|c|c|}
\hline Source & $\begin{array}{c}\text { Brain Region } \\
\text { Quantified }\end{array}$ & $\mathrm{df}$ & $\mathrm{F}$ & P-Value \\
\hline \multirow[t]{11}{*}{$\begin{array}{c}\text { Route of Administration } \\
\text { (DID or i.p.) }\end{array}$} & dBNST & 1,8 & 2.077 & 0.188 \\
\hline & vBNST & 1,8 & 0.396 & 0.547 \\
\hline & $\mathrm{CeA}$ & 1,8 & 0.428 & 0.531 \\
\hline & BLA & 1,8 & 13.469 & 0.006 \\
\hline & PVA & 1,8 & 0.543 & 0.482 \\
\hline & PVT & 1,8 & 0.405 & 0.542 \\
\hline & $\mathrm{LH}$ & 1,8 & 15.312 & 0.004 \\
\hline & EW & 1,8 & 8.322 & 0.020 \\
\hline & $\mathrm{LC}$ & 1,8 & 5.874 & 0.042 \\
\hline & lPBn & 1,8 & 12.026 & 0.008 \\
\hline & $\mathrm{A} 2$ & 1,8 & 21.851 & 0.002 \\
\hline \multirow[t]{11}{*}{$\begin{array}{c}\text { Solution } \\
\text { (Vehicle or Ethanol } \\
\text { Binge) } \\
\end{array}$} & dBNST & 1,8 & 20.495 & 0.002 \\
\hline & vBNST & 1,8 & 23.328 & 0.001 \\
\hline & $\mathrm{CeA}$ & 1,8 & 5.847 & 0.042 \\
\hline & BLA & 1,8 & 12.725 & 0.007 \\
\hline & PVA & 1,8 & 1.564 & 0.246 \\
\hline & PVT & 1,8 & 5.058 & 0.055 \\
\hline & $\mathrm{LH}$ & 1,8 & 7.967 & 0.022 \\
\hline & EW & 1,8 & 85.694 & $<0.001$ \\
\hline & $\mathrm{LC}$ & 1,8 & 20.796 & 0.002 \\
\hline & $1 \mathrm{PBn}$ & 1,8 & 0.472 & 0.512 \\
\hline & $\mathrm{A} 2$ & 1,8 & 17.421 & 0.003 \\
\hline \multirow[t]{11}{*}{ Interaction } & dBNST & 1,8 & 1.738 & 0.224 \\
\hline & vBNST & 1,8 & 0.285 & 0.608 \\
\hline & $\mathrm{CeA}$ & 1,8 & 1.172 & 0.310 \\
\hline & BLA & 1,8 & 1.38 & 0.274 \\
\hline & PVA & 1,8 & 0.346 & 0.573 \\
\hline & PVT & 1,8 & 0.631 & 0.450 \\
\hline & LH & 1,8 & 0.268 & 0.619 \\
\hline & EW & 1,8 & 0.018 & 0.895 \\
\hline & $\mathrm{LC}$ & 1,8 & 1.584 & 0.244 \\
\hline & IPBn & 1,8 & 0.58 & 0.816 \\
\hline & $\mathrm{A} 2$ & 1,8 & 2.05 & 0.190 \\
\hline
\end{tabular}

Bolded $\mathrm{p}$-values indicate significance $(\mathrm{p}<0.05)$. Regions analyzed were dBNST, dorsal bed nucleus of the stria terminalis; vBNST, ventral bed nucleus of the stria terminalis; CeA, central amygdala; BLA, basolateral amygdala; PVA, anterior paraventricular nucleus of the thalamus; PVT, paraventricular nucleus of the thalamus; LH, lateral hypothalamus; EW, 
Edinger-Westphal nucleus; LC, locus coeruleus; IPBn, lateral parabrachial nucleus; A2, A2 nucleus of the nucleus tractus solitarus (NTS). 
Figure 1: C-Fos immunoexpression following voluntary and forced binge episodes. A) Voluntary binge-like ethanol consumption (20\% ethanol during $2 \mathrm{hr}$ DID test day) significantly increases c-Fos immunoexpression in the dBNST, vBNST, CeA, PVT, LH, EW, LC, and A2 region of the NTS relative to water-consuming controls. B) $1.5 \mathrm{~g} / \mathrm{kg}$ ethanol $(13 \% \mathrm{v} / \mathrm{v})$ delivered IP significantly increased c-Fos immunoexpression in dBNST, vBNST, CeA, BLA, PVT, LH, EW, LC and the A2 region of the NTS relative to saline-injected controls. All values are mean \pm SEM. \# signifies $\mathrm{p}<0.01 ; *$ signifies $\mathrm{p}<0.05$.
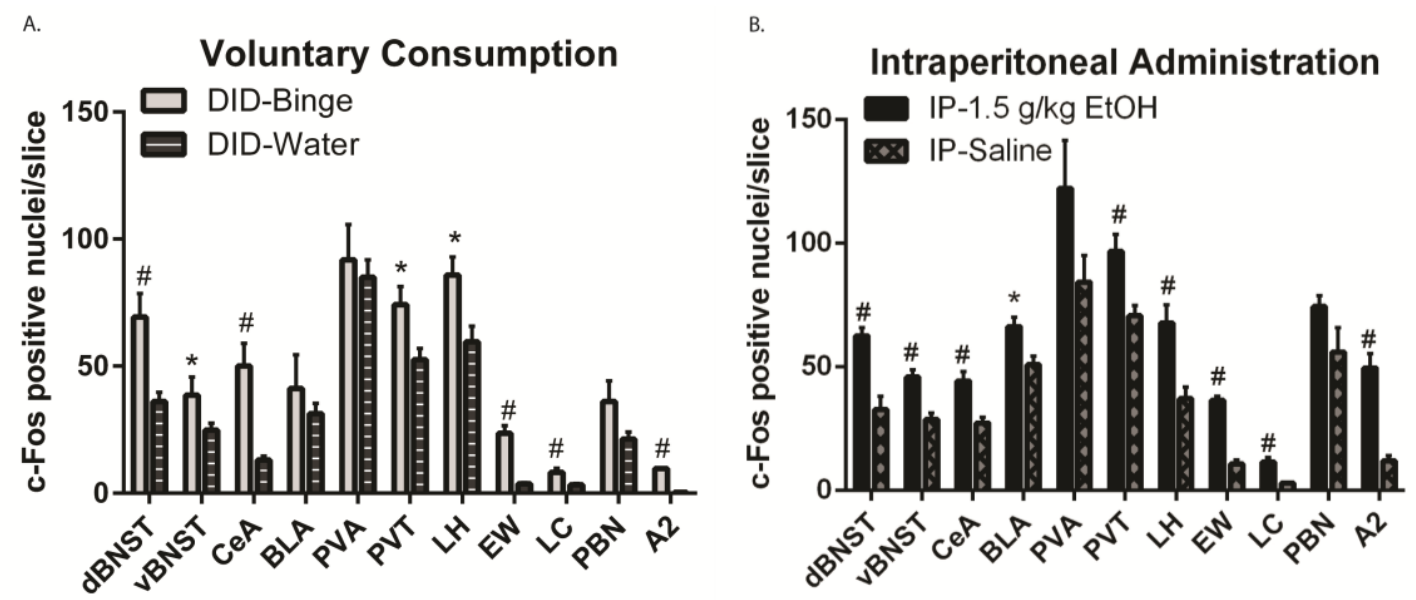
Figure 2: Representative photomicrographs from brain regions where significant c-Fos differences were observed between animals voluntarily binging or consuming water. A) dorsal bed nucleus of the stria terminals (dBNST); B) Ventral bed nucleus of the stria terminalis (vBNST); C) Central amygdala (CeA); D) Paraventricular nucleus of the thalamus (PVT); E) Lateral hypothalamus (LH); F) Edinger-Westphal nucleus (EW); G) Locus coeruleus (LC); H) A2 region of the NTS. In A-F, outlined areas represent approximate regions of c-Fos IR quantification. A-F imaged at 20x whereas G-H imaged at 40x, with scale bars denoting 0.1 mm. Representative c-Fos and TH co-expression indicated by black arrowheads.
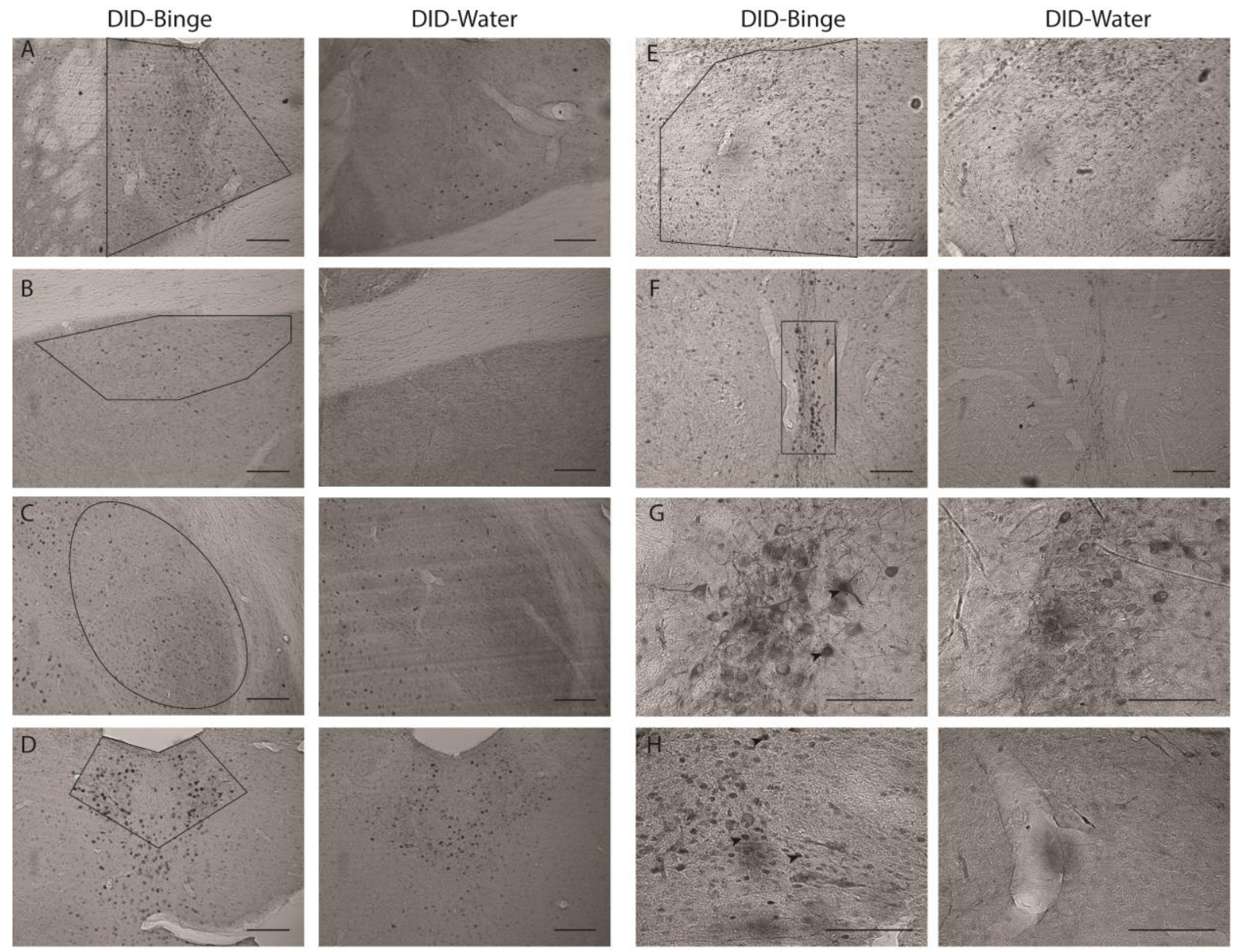
Figure 3: Representative photomicrographs from brain regions where significant c-Fos differences were observed in animals receiving a forced binge (i.p. ethanol) or saline injection. A) dorsal bed nucleus of the stria terminals (dBNST); B) Ventral bed nucleus of the stria terminalis (vBNST); C) Central amygdala (CeA); D) Basolateral amygdala (BLA); E) Paraventricular nucleus of the thalamus (PVT); F) Lateral hypothalamus (LH); G) EdingerWestphal nucleus (EW); H) Locus coeruleus (LC); I) A2 region of the NTS. In A-G, outlined areas represent approximate regions of c-Fos IR quantification. A-G imaged at 20x whereas H-I imaged at 40x, with scale bars denoting $0.1 \mathrm{~mm}$. Representative c-Fos and TH coexpression indicated by black arrowheads.
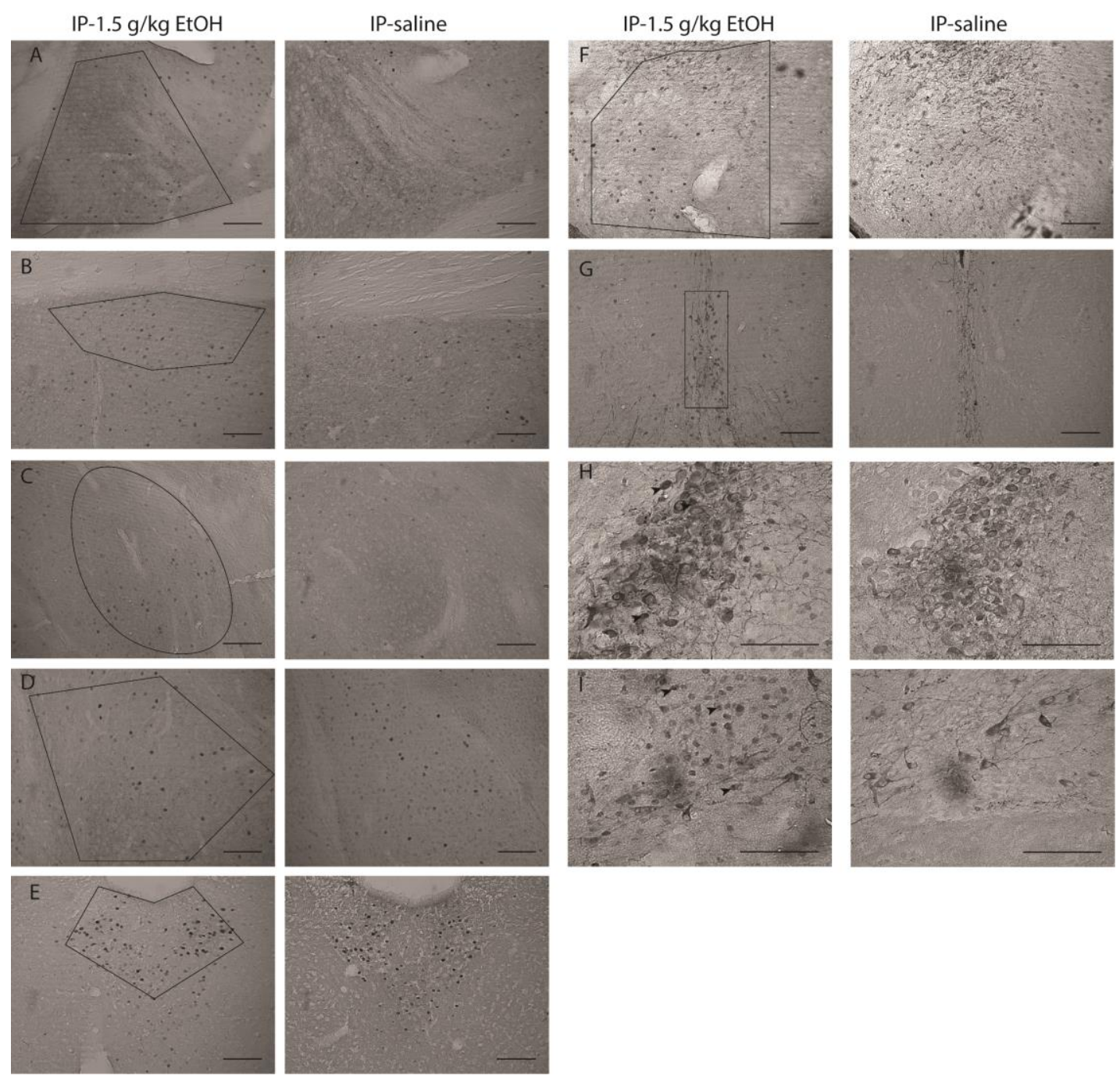


\section{REFERENCES}

Albrechet-Souza L, Hwa LS, Han X, Zhang EY, DeBold JF, Miczek KA (2015)

Corticotropin Releasing Factor Binding Protein and CRF2 Receptors in the Ventral Tegmental Area: Modulation of Ethanol Binge Drinking in C57BL/6J Mice. Alcohol Clin Exp Res 39:1609-1618.

Aronin N, Sagar SM, Sharp FR, Schwartz WJ (1990) Light regulates expression of a Fosrelated protein in rat suprachiasmatic nuclei. Proc Natl Acad Sci U S A 87:59595962.

Bachtell RK, Wang YM, Freeman P, Risinger FO, Ryabinin AE (1999) Alcohol drinking produces brain region-selective changes in expression of inducible transcription factors. Brain Res 847:157-165.

Caterina MJ, Schumacher MA, Tominaga M, Rosen TA, Levine JD, Julius D (1997) The capsaicin receptor: a heat-activated ion channel in the pain pathway. Nature 389:816824.

Ceccatelli S, Villar MJ, Goldstein M, Hokfelt T (1989) Expression of c-Fos immunoreactivity in transmitter-characterized neurons after stress. Proc Natl Acad Sci U S A 86:9569-9573.

Chandler DJ, Gao WJ, Waterhouse BD (2014) Heterogeneous organization of the locus coeruleus projections to prefrontal and motor cortices. Proc Natl Acad Sci U S A 111:6816-6821.

Choi S, Wong LS, Yamat C, Dallman MF (1998) Hypothalamic ventromedial nuclei amplify circadian rhythms: do they contain a food-entrained endogenous oscillator? J Neurosci 18:3843-3852.

Delfs JM, Zhu Y, Druhan JP, Aston-Jones G (2000) Noradrenaline in the ventral forebrain is critical for opiate withdrawal-induced aversion. Nature 403:430-434.

Ellingson JM, Silbaugh BC, Brasser SM (2009) Reduced oral ethanol avoidance in mice lacking transient receptor potential channel vanilloid receptor 1. Behav Genet 39:6272. 
Fan AZ, Russell M, Stranges S, Dorn J, Trevisan M (2008) Association of lifetime alcohol drinking trajectories with cardiometabolic risk. J Clin Endocrinol Metab 93:154-161.

Foote SL, Bloom FE, Aston-Jones G (1983) Nucleus locus ceruleus: new evidence of anatomical and physiological specificity. Physiol Rev 63:844-914.

Franklin KBJ, Paxinos G (1997) The Mouse Brain in Stereotaxic Coordinates, Academic Press, San Diego, CA.

Gmel G, Bissery A, Gammeter R, Givel JC, Calmes JM, Yersin B, Daeppen JB (2006) Alcohol-attributable injuries in admissions to a swiss emergency room--an analysis of the link between volume of drinking, drinking patterns, and preattendance drinking. Alcohol Clin Exp Res 30:501-509.

Grassi-Zucconi G, Menegazzi M, De Prati AC, Bassetti A, Montagnese P, Mandile P, Cosi C, Bentivoglio M (1993) c-fos mRNA is spontaneously induced in the rat brain during the activity period of the circadian cycle. Eur J Neurosci 5:1071-1078.

Hingson R, Heeren T, Winter M, Wechsler H (2005) Magnitude of alcohol-related mortality and morbidity among U.S. college students ages 18-24: changes from 1998 to 2001. Annu Rev Public Health 26:259-279.

Hwa LS, Chu A, Levinson SA, Kayyali TM, DeBold JF, Miczek KA (2011) Persistent escalation of alcohol drinking in C57BL/6 J mice with intermittent access to $20 \%$ ethanol. Alcohol Clin Exp Res 35:1938-1947.

Kelley AE, Baldo BA, Pratt WE (2005) A proposed hypothalamic-thalamic-striatal axis for the integration of energy balance, arousal, and food reward. J Comp Neurol 493:7285.

Knapp DJ, Braun CJ, Duncan GE, Qian Y, Fernandes A, Crews FT, Breese GR (2001) Regional specificity of ethanol and NMDA action in brain revealed with FOS-like immunohistochemistry and differential routes of drug administration. Alcohol Clin Exp Res 25:1662-1672. 
Lee S, Craddock Z, Rivier C (2011) Brain stem catecholamines circuitry: activation by alcohol and role in the hypothalamic-pituitary-adrenal response to this drug. $\mathrm{J}$ Neuroendocrinol 23:531-541.

Leriche M, Mendez M, Zimmer L, Berod A (2008) Acute ethanol induces Fos in GABAergic and non-GABAergic forebrain neurons: a double-labeling study in the medial prefrontal cortex and extended amygdala. Neuroscience 153:259-267.

Li J, Cheng Y, Bian W, Liu X, Zhang C, Ye JH (2010) Region-specific induction of FosB/DeltaFosB by voluntary alcohol intake: effects of naltrexone. Alcohol Clin Exp Res 34:1742-1750.

Lowery-Gionta EG, Navarro M, Li C, Pleil KE, Rinker JA, Cox BR, Sprow GM, Kash TL, Thiele TE (2012) Corticotropin releasing factor signaling in the central amygdala is recruited during binge-like ethanol consumption in C57BL/6J mice. J Neurosci 32:3405-3413.

Mejias-Aponte CA, Drouin C, Aston-Jones G (2009) Adrenergic and noradrenergic innervation of the midbrain ventral tegmental area and retrorubral field: prominent inputs from medullary homeostatic centers. J Neurosci 29:3613-3626.

Middaugh LD, Kelley BM (1999) Operant ethanol reward in C57BL/6 mice: influence of gender and procedural variables. Alcohol 17:185-194.

Miller JW, Naimi TS, Brewer RD, Jones SE (2007) Binge drinking and associated health risk behaviors among high school students. Pediatrics 119:76-85.

Naimi TS, Brewer RD, Mokdad A, Denny C, Serdula MK, Marks JS (2003) Binge drinking among US adults. JAMA 289:70-75.

Olney JJ, Navarro M, Thiele TE (2015) Binge-like consumption of ethanol and other salient reinforcers is blocked by orexin-1 receptor inhibition and leads to a reduction of hypothalamic orexin immunoreactivity. Alcohol Clin Exp Res 39:21-29.

Pleil KE, Rinker JA, Lowery-Gionta EG, Mazzone CM, McCall NM, Kendra AM, Olson DP, Lowell BB, Grant KA, Thiele TE, Kash TL (2015) NPY signaling inhibits 
extended amygdala CRF neurons to suppress binge alcohol drinking. Nat Neurosci 18:545-552.

Rhodes JS, Best K, Belknap JK, Finn DA, Crabbe JC (2005) Evaluation of a simple model of ethanol drinking to intoxication in C57BL/6J mice. Physiol Behav 84:53-63.

Rhodes JS, Ford MM, Yu CH, Brown LL, Finn DA, Garland T, Jr., Crabbe JC (2007) Mouse inbred strain differences in ethanol drinking to intoxication. Genes Brain Behav 6:118.

Rubinsky AD, Kivlahan DR, Volk RJ, Maynard C, Bradley KA (2010) Estimating risk of alcohol dependence using alcohol screening scores. Drug Alcohol Depend 108:29-36.

Ryabinin AE, Galvan-Rosas A, Bachtell RK, Risinger FO (2003) High alcohol/sucrose consumption during dark circadian phase in C57BL/6J mice: involvement of hippocampus, lateral septum and urocortin-positive cells of the Edinger-Westphal nucleus. Psychopharmacology (Berl) 165:296-305.

Sajja RK, Rahman S (2013) Cytisine modulates chronic voluntary ethanol consumption and ethanol-induced striatal up-regulation of DeltaFosB in mice. Alcohol 47:299-307.

Sharp FR, Sagar SM, Hicks K, Lowenstein D, Hisanaga K (1991) c-fos mRNA, Fos, and Fos-related antigen induction by hypertonic saline and stress. J Neurosci 11:23212331.

Sharpe AL, Tsivkovskaia NO, Ryabinin AE (2005) Ataxia and c-Fos expression in mice drinking ethanol in a limited access session. Alcohol Clin Exp Res 29:1419-1426.

Smith RJ, Aston-Jones G (2008) Noradrenergic transmission in the extended amygdala: role in increased drug-seeking and relapse during protracted drug abstinence. Brain Struct Funct 213:43-61.

Sprow GM, Thiele TE (2012) The neurobiology of binge-like ethanol drinking: evidence from rodent models. Physiol Behav 106:325-331. 
Szallasi A, Blumberg PM (2007) Complex Regulation of TRPV1 by Vanilloids, in TRP Ion Channel Function in Sensory Transduction and Cellular Signaling Cascades, TRP Ion Channel Function in Sensory Transduction and Cellular Signaling Cascades (LIEDTKE WB, HELLER S eds), Boca Raton (FL).

Thiele TE, Cubero I, van Dijk G, Mediavilla C, Bernstein IL (2000) Ethanol-induced c-fos expression in catecholamine- and neuropeptide Y-producing neurons in rat brainstem. Alcohol Clin Exp Res 24:802-809.

Thiele TE, Navarro M (2014) "Drinking in the dark" (DID) procedures: a model of binge-like ethanol drinking in non-dependent mice. Alcohol 48:235-241.

Trevisan G, Rossato MF, Hoffmeister C, Oliveira SM, Silva CR, Matheus FC, Mello GC, Antunes E, Prediger RD, Ferreira J (2013) Mechanisms involved in abdominal nociception induced by either TRPV1 or TRPA1 stimulation of rat peritoneum. Eur J Pharmacol 714:332-344.

Turek VF, Ryabinin AE (2005) Expression of c-Fos in the mouse Edinger-Westphal nucleus following ethanol administration is not secondary to hypothermia or stress. Brain Res 1063:132-139.

Vetter-O'Hagen C, Varlinskaya E, Spear L (2009) Sex differences in ethanol intake and sensitivity to aversive effects during adolescence and adulthood. Alcohol Alcohol 44:547-554.

Weitemier AZ, Woerner A, Backstrom P, Hyytia P, Ryabinin AE (2001) Expression of c-Fos in Alko alcohol rats responding for ethanol in an operant paradigm. Alcohol Clin Exp Res 25:704-710.

Yoneyama N, Crabbe JC, Ford MM, Murillo A, Finn DA (2008) Voluntary ethanol consumption in 22 inbred mouse strains. Alcohol 42:149-160. 